\title{
Are errors ubiquitous in cardiac surgery?
}

\author{
Emile Bacha, MD
}

See related article on pages 496-507.

Experienced cardiac surgeons know that once a deviation from the ideal clinical path has occurred (eg, revision of a coronary transfer in an arterial switch operation), the safety margin shrinks, and the odds of the patient surviving without any complications are reduced. This knowledge is visceral and comes mainly from experience. The study gives objective evidence for this phenomenon and others related to safety in the practice of pediatric cardiac surgery. It builds on the Toronto's Hospital for Sick Children tradition of safety studies, ${ }^{1}$ and looks at the cycles of errors that lead to poor outcomes. The authors use the aviation industry's "threat and error model," developed from line operation safety audits that are used to analyze the negative events leading to air crashes. The authors show that deaths are almost always preceded by cycles of errors and that human errors (if not neutralized) often lead to those cycles.

Other interesting findings include the fact that a high RACHS (risk adjustment for congenital heart surgery) category, the presence of preoperative risk factors ("baseline threats" in their language), and intraoperative events (the most important being need for surgical revision, having to abort the primary plan, and need for an additional unplanned procedure) were associated with error cycles. Although other investigators have found this, ${ }^{2}$ the interesting thing is that the authors measured the impact of human factors (which are typically difficult to define precisely) on these events, and then on outcomes. The most sobering finding is that "fewer than $10 \%$ of all patient journeys proceeded as the metaphorical ideal with no patient threats, errors or intended states." Other sobering findings: Consequential errors (leading to undesirable clinical situations, or in their language, "unintended states") occurred in one third of cases, whereas error cycles (which resulted in major morbidity or death in $85 \%$ of cases) occurred in one fifth of all cases.

One might look at these findings and think that this program is of low quality. Yet, by traditional methods of

\footnotetext{
From the Division of Cardiothoracic Surgery, Morgan Stanley Children's Hospital of New York, Columbia University, New York, NY.

Disclosures: Author has nothing to disclose with regard to commercial support.

Received for publication Nov 9, 2014; accepted for publication Nov 10, 2014; available ahead of print Dec 6, 2014.

Address for reprints: Emile Bacha, MD, Congenital and Pediatric Cardiac Surgery,

Morgan Stanley Children's Hospital of New York, Columbia University,

New York, NY 10032 (E-mail: eb2709@cumc.columbia.edu).

J Thorac Cardiovasc Surg 2015;149:411

$0022-5223 / \$ 36.00$

Copyright $(2015$ Published by Elsevier Inc. on behalf of The American Association for Thoracic Surgery

http://dx.doi.org/10.1016/j.jtcvs.2014.11.022
}

measuring quality, given that their non-risk adjusted surgical mortality is $<2 \%$, they would be considered a top program, which they no doubt are. This leads to the realization that their seemingly depressing data showing high error rates can be applied to all programs, a very sobering thought indeed.

What can be done about this? Are we to just accept the fact that pediatric cardiac surgery is inherently dangerous and error prone? Other industries, such as aviation or nuclear industries, have been able to reduce the burden of errors to an extremely low level. However, medicine (at least not clinical medicine) is not an industry, and we deal with an infinite variety of human conditions (as opposed to pilots who deal with standardized planes). Therefore, the parallels with these industries, as pointed out by the authors, are limited.

It may be time for a paradigm shift in surgical safety, becoming independent of the aviation industry models of safety. In the meantime, we can agree that the authors have demonstrated that the development of safety can best occur in programs in which constructive self-criticism, self-awareness, collegiality, avoidance of blame, openness, and relentless pursuit of excellence are seen as virtues. Debriefings, crew resource management, "failure to rescue" evaluations, and widespread program-wide top-to-bottom education in surgical safety are some of the basic techniques that should be used everywhere.

Although I commend the authors on their important work, one negative aspect of the study is that the auditing technique they utilize is impractical, time consuming, and requires dedicated personnel with specialized knowledge, which are unlikely to be had in smaller programs at a time of shrinking budgets. One could envision a future when, moving beyond databases and risk-adjusted mortality measures, our national societies (Society of Thoracic Surgeons, American Association for Thoracic Surgery, Congenital Heart Surgeons Society) would get in the business of periodically sending specialized safety observers to each program, to observe and accredit. This method of assessing a center's proficiency would be more comprehensive, and more importantly, would have a much greater impact on patient outcomes than currently used methods.

\section{References}

1. Jacques F, Anand V, Hickey EJ, Kotani Y, Yadava M, Alghamdi A, et al. Medical errors: the performance gap in hypoplastic left heart syndrome and physiologic equivalents? J Thorac Cardiovasc Surg. 2013;145:1465-73.

2. Barach P, Johnson JK, Ahmad A, Galvan C, Bognar A, Duncan R, et al. A prospective observational study of human factors, adverse events, and patient outcomes in surgery for pediatric cardiac disease. J Thorac Cardiovasc Surg. 2008; 136:1422-8 